Journal of Mechanical Engineering and Sciences (JMES)

ISSN (Print): 2289-4659; e-ISSN: 2231-8380; Volume 1, pp. 37-46, December 2011

(C) Universiti Malaysia Pahang, Pekan, Pahang, Malaysia

DOI: http://dx.doi.org/10.15282/jmes.1.2011.4.0004

\title{
FINITE ELEMENT ANALYSIS OF HASTELLOY C-22HS IN END MILLING
}

\author{
K. Kadirgama, M.M. Rahman, A.R. Ismail and R.A. Bakar \\ Faculty of Mechanical Engineering \\ Universiti Malaysia Pahang \\ 26600 Pekan, Pahang, Malaysia \\ Phone: +6094242355; Fax: +6094242202 \\ Email: kumaran@ump.edu.my
}

\begin{abstract}
This paper presents a finite element analysis of the stress distribution in the end milling operation of nickel-based superalloy HASTELLOY C-2000. Commercially available finite element software was used to develop the model and analyze the distribution of stress components in the machined surface of HASTELLOY C-22HS following end milling with coated carbide tools. The friction interaction along the tool-chip interface was modeled using the Coulomb friction law. It was found that the stress had lower values under the cut surface and that it increased gradually near the cutting edge.
\end{abstract}

Keywords: Finite element analysis; stress; nickel based superalloy; end milling.

\section{INTRODUCTION}

In many industries, nickel-based alloys represent an important segment of structural materials. Critical components made of these alloys are often relied upon to function satisfactorily in corrosive environments. Highly corrosion-resistant alloy castings are often the subject of major concern because failures of cast components can lead to significant downtime costs and operating problems (Strenkowski \& Carroll, 1985). Over the years, nickel-chromium-molybdenum/tungsten alloys have proven to be among the most reliable and cost-effective materials for aggressive seawater applications with excellent resistance to localized corrosive attack (pitting, crevice corrosion). Among these alloys, HASTELLOY C-types (C, C-4, C-276, and C-22) are often used to serve the above-mentioned purposes. As these alloys are commonly subject to further machining after casting, it becomes vital to understand the changes in properties imparted to the machined surfaces following cutting operations such as end milling. For this reason, the finite element methodology is used in this study to determine the machined surface stress characteristics. In the past decade, the finite element method, based on the updated-Lagrangian formulation, has been developed to analyze metal cutting processes (Strenkowski \& Carroll, 1985; Shih, Chandrasekar \& Yang, 1990). Several special finite element techniques, such as element separation (Komvopoulos \& Erpenbeek, 1991; Shih \& Yang, 1993), the modeling of worn cutting tool geometry (Komvopoulos \& Erpenbeek, 1991; Shih \& Yang, 1993; Shih, 1996), mesh rezoning (Komvopoulos \& Erpenbeek, 1991; Ueda \& Manabe, 1993), and friction modeling (Strenkowski \& Carroll, 1985; Komvopoulos \& Erpenbeek, 1991), etc., have been implemented to improve the accuracy and efficiency of finite element modeling. Detailed work-material modeling, which includes the coupling of temperature, strain rate, and strain-hardening effects, has been applied to model material deformation (Shih et al., 1990; Shih \& Yang, 1993; Shih, 1996). An early analytical model for predicting residual stresses was proposed by Okushima and Kakino (1971), in which residual 
stresses were related to the cutting force and temperature distribution during machining. In another analytical model, a relation was derived between residual stresses and the hardness of the workpiece (Wu \& Matsumoto, 1990). Shih and Yang (1993) conducted a combined experimental/computational study of the distribution of residual stresses in a machined workpiece. Liu \& Guo (2000) used the finite element method to evaluate residual stresses in a workpiece. They also observed that the magnitude of residual stress is reduced when a second cut is made on the cut surface. Liu and Barash (1982) measured the residual stress on the workpiece subsurface with consideration of tool flank wear. Their findings indicated that under the condition of a lower cutting speed, the mechanical load had a greater impact on residual stress, whereas the thermal effect become the major factor affecting residual stress at higher cutting speed. Lee and Shaffer (1951) proposed a shear-angle model based on the slip-line field theory, which assumes a rigid perfectly plastic material behavior and a straight shear plane. Kudo (1965) modified the slip-line model by introducing a curved shear plane to account for the controlled contact between the curved chip and straight tool face. Henriksen (1951) conducted a series of tests to understand residual stresses in the machined surface of steel and cast iron parts under various cutting conditions. Kono, Hara, Yazu, Uchida, and Mori (1980), and Tonshoff, Wobker, and Brandt (1995) revealed that residual stresses are dependent on the cutting speed. Matsumoto, Barash \& Liu (1986) and Wu and Matsumoto (1990) observed that the hardness of the workpiece material has a significant influence on the residual stress field. Konig, Berktold, and Koch (1993) showed that friction in metal cutting also contributes to the formation of residual stresses.

\section{FINITE ELEMENT MODEL}

The finite element model (FEM) is composed of a deformable workpiece and a rigid tool. The tool penetrates through the workpiece at a constant speed and constant feed rate. The model assumes plane-strain conditions because generally, the depth of cut is much greater than the feed rate. The FEM used in this study is based on commercially available finite element software called "Thirdwave AdvantEdge". It uses six-noded quadratic triangular elements by default. AdvantEdge is an automated program and it is sufficient to input process parameters in order to construct a two-dimensional simulation of an orthogonal cutting operation. Thermal boundary conditions for Thirdwave AdvantEdge are given as:

1. The heat is generated because of the heavy plastic work done on the workpiece. Its formula is given in Eq. (1):

$$
R=\frac{m \cdot f \cdot W^{P}}{\rho}
$$

where $W^{P}$ is the rate of plastic work, $f$ is the fraction of plastic work converted into heat (assumed to be 0.9), $m$ is the mechanical equivalent of heat (taken as 1), and $\rho$ is the density of the workpiece material $\left(8.6 \mathrm{~g} / \mathrm{cm}^{3}\right)$

2. The heat is generated because of friction between the chip and the rake face of the tool according to Eq. (2): 


$$
q=F_{f r} \cdot V_{r} \cdot m
$$

where $F_{f r}$ is the friction force, $V_{r}$ is the relative sliding velocity between the tool and chip, and $m$ is the mechanical equivalent of heat $(m=1)$

3. The generated frictional heat is distributed to the chip and tool according to Eq. (3):

$$
\frac{Q_{\text {chip }}}{Q_{\text {tool }}}=\frac{\sqrt{k_{\text {chip }} \cdot \rho_{\text {chip }} \cdot c_{\text {chip }}}}{\sqrt{k_{\text {tool }} \cdot \rho_{\text {tool }} \cdot c_{\text {too }} l}}
$$

where $Q_{\text {chip }}$ is the heat given to the chip, $Q_{\text {tool }}$ is the heat given to the tool, $k$ is the conductivity, $\rho$ is the density, and $c$ is the heat capacity.
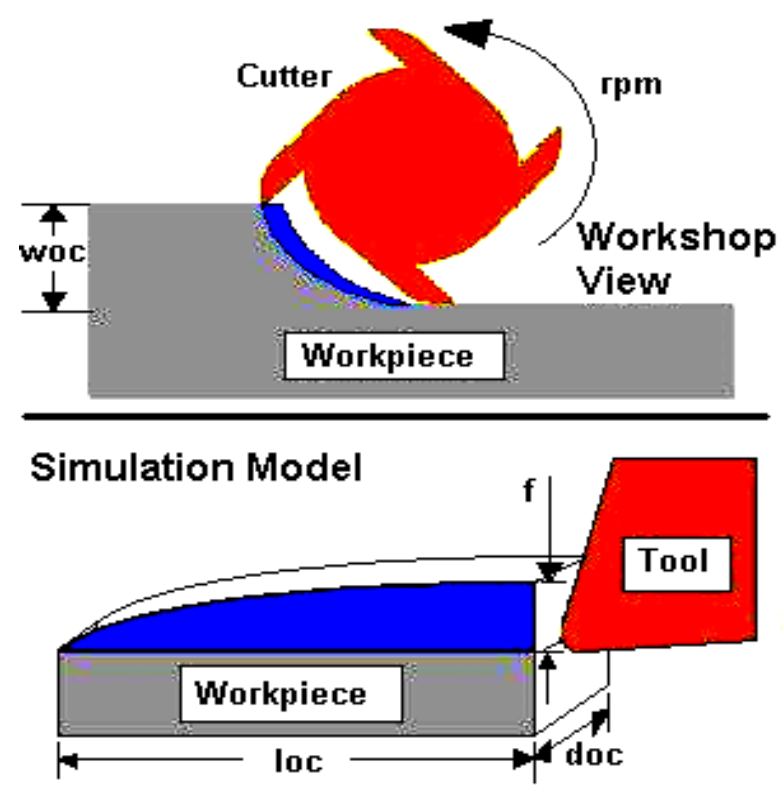

Figure 1. Model for milling

Certain assumptions are made in simulating the complex procedure of metal cutting with FEM. These assumptions are used to define the problem to be solved, as well as to apply the boundary and loading conditions:

1. The cutting speed is constant.

2. The width of cut is larger than the feed (plane strain condition), and both are constant.

3. The cutting velocity vector is normal to the cutting edge.

4. The workpiece material is a homogeneous polycrystalline, isotropic, and incompressible solid.

5. The workpiece is set at a reference temperature of $20^{\circ} \mathrm{C}$ at the beginning of simulation.

6. The machine tool is perfectly rigid and there is no influence of machine tool dynamics on the machining.

7. There is constant friction between the tool-chip interaction and the toolworkpiece interaction. 
Figure 1 shows the Thirdwave AdvantEdge model for a milling operation and Figure 2 shows an example of a visual simulation of residual stresses induced after milling.

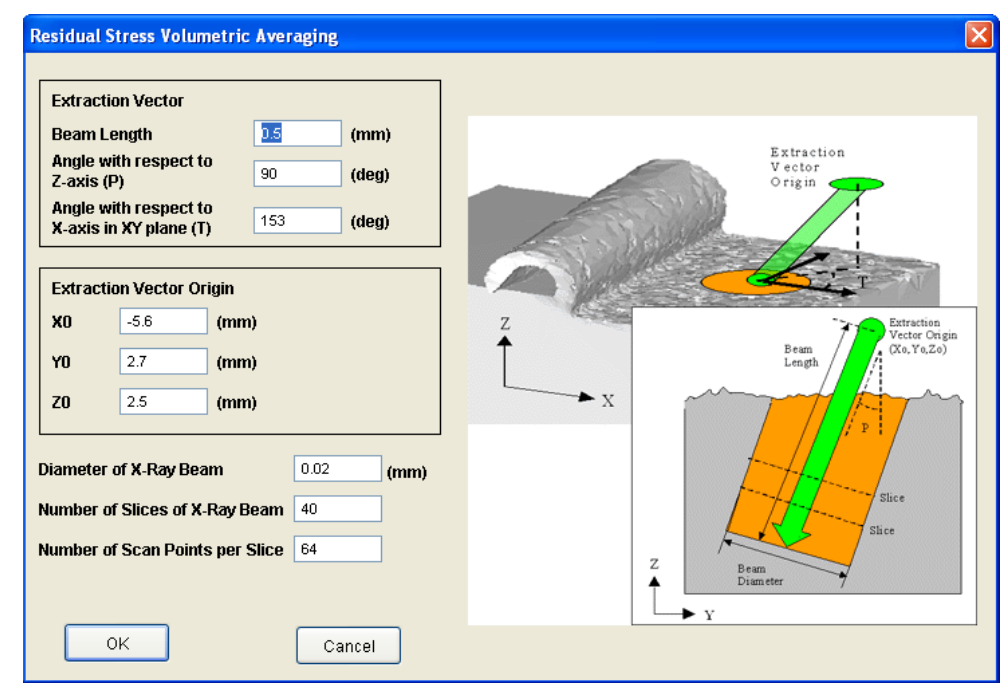

Figure 2. Model of residual stress

\section{WORKPIECE AND TOOL MATERIAL MODELING}

The workpiece material used for the simulation is HASTELLOY C-22HS, the cutting tool is carbide coated with TiALN and with a $20^{\circ}$ rake angle. After each pass $(80 \mathrm{~mm})$, the simulation was stopped. AdvantEdge uses an analytical formulation for material modeling. In a typical machining event, in the primary and secondary shear zones, very high strain rates are achieved, whereas the remainder of the workpiece deforms at moderate or low strain rates. In order to account for this, Thirdwave AdvantEdge incorporates a stepwise variation of the rate sensitivity exponent:

$$
\bar{\sigma}=\sigma_{f}\left(\varepsilon^{p}\right) \cdot\left(1+\frac{\dot{\varepsilon}^{p}}{\dot{\varepsilon}_{o}^{p}}\right)^{1 / m_{1}} \text {, if } \dot{\mathcal{E}} \leq \dot{\varepsilon}_{t}^{p}
$$

where $\bar{\sigma}$ is the effective von Mises stress, $\sigma_{f}$ is the flow stress, $\varepsilon^{p}$ is the accumulated plastic strain, $\dot{\varepsilon}_{o}^{p}$ is a reference plastic strain rate, $m_{1}$ is the strain rate sensitivity exponents, and $\dot{\varepsilon}_{t}$ is the threshold strain rate that separates the two regimes. In the calculations, a local Newton-Raphson iteration is used to compute $\dot{\varepsilon}_{o}^{p}$ according to the low rate equation, which switches to the high rate equation if the result lies above $\dot{\varepsilon}_{t}$. $\sigma_{f}$, which is used in Eq. (5), is given as:

$$
\sigma_{f}=\sigma_{0} \cdot \psi(T) \cdot\left(1+\frac{\varepsilon^{p}}{\varepsilon_{0}^{p}}\right)^{1 / n}
$$

where $T$ is the current temperature, $\sigma_{0}$ is the initial yield stress at the reference temperature $T_{0}, \varepsilon_{0}^{p}$ is the reference plastic strain, $n$ is the hardening exponent, and $\psi(T)$ 
is the thermal softening factor. In the present study, it is assumed that the tool is not plastifying; hence, it is considered as an absolutely rigid body.

\section{Workpiece Material}

The properties of the workpiece material (HASTELLOY C-22HS) are shown in Tables 1 and 2, and the cutting tool properties and simulation are shown in Tables 3 and 4.

Table 1. Chemical composition for HASTELLOY C-22HS.

\begin{tabular}{lllllllllll}
\hline $\mathrm{Ni}$ & $\mathrm{Cr}$ & $\mathrm{Mo}$ & $\mathrm{Fe}$ & $\mathrm{Co}$ & $\mathrm{W}$ & $\mathrm{Mn}$ & $\mathrm{Al}$ & $\mathrm{Si}$ & $\mathrm{C}$ & $\mathrm{B}$ \\
\hline $\mathrm{BAL}(\%)$ & 21 & 17 & 2 & 1 & 1 & 0.80 & 0.50 & 0.08 & 0.01 & 0.01 \\
\hline
\end{tabular}

Table 2. Physical properties of HASTELLOY C-22HS at room temperature

\begin{tabular}{ll}
\hline Properties & Value \\
\hline Density $\left(\mathrm{g} / \mathrm{cm}^{3}\right)$ & 8.6 \\
Thermal Conductivity $\left(\mathrm{W} / \mathrm{m} .{ }^{\circ} \mathrm{C}\right)$ & 11.8 \\
Mean Coefficient of Thermal Expansion $\left(\mu \mathrm{m} / \mathrm{m} .{ }^{\circ} \mathrm{C}\right)$ & 11.6 \\
Thermal Diffusivity $\left(\mathrm{cm}^{2} / \mathrm{s}\right)$ & 0.0334 \\
Specific Heat $\left(\mathrm{J} / \mathrm{kg} .{ }^{\circ} \mathrm{C}\right)$ & 412 \\
Young Modulus $(\mathrm{GPa})$ & 223 \\
\hline
\end{tabular}

Table 3. Cutting tool properties

\begin{tabular}{ccccccccc}
\hline $\begin{array}{c}\text { Code } \\
\text { name }\end{array}$ & \multicolumn{5}{c}{ Composition (\%) } & & Coating & $\begin{array}{c}\text { Thickness } \\
(\mu \mathrm{m})\end{array}$ \\
\hline & $\% \mathrm{Co}$ & $\% \mathrm{WC}$ & $\% \mathrm{Cr} 3 \mathrm{C} 2$ & $\% \mathrm{TaC}$ & $\% \mathrm{TiC}$ & $\% \mathrm{Nbc}$ & & \\
$\mathrm{KC5} 20 \mathrm{M}$ & 6 & 93.5 & 0.5 & - & - & - & PVD & 3.5 \\
\hline
\end{tabular}

Table 4. Simulation conditions

\begin{tabular}{llll}
\hline Simulation No. & Cutting speed & Feed rate & Axial depth \\
\hline 1 & 140 & 0.1 & 2 \\
2 & 140 & 0.2 & 1 \\
3 & 100 & 0.15 & 1 \\
4 & 100 & 0.15 & 2 \\
5 & 140 & 0.15 & 1.5 \\
6 & 100 & 0.1 & 1.5 \\
7 & 180 & 0.1 & 1.5 \\
8 & 180 & 0.15 & 2 \\
9 & 180 & 0.2 & 1.5 \\
10 & 140 & 0.2 & 2 \\
11 & 180 & 0.15 & 1 \\
12 & 140 & 0.15 & 1.5 \\
13 & 140 & 0.1 & 1 \\
14 & 100 & 0.2 & 1.5 \\
15 & 140 & 0.15 & 1.5 \\
\hline
\end{tabular}




\section{RESULTS AND DISCUSSION}

The von Mises stress $\sigma_{V}$, is used to estimate yield criteria for ductile materials. It is calculated by combining stresses in two or three dimensions with the result compared with the tensile strength of the material loaded in one dimension. The von Mises stress is also useful for calculating the fatigue strength (Schey, 2000).

The von Mises stress in three dimensions is expressed as (Schey, 2000):

$$
\sigma_{V}=\sqrt{\frac{\left(\sigma_{1}-\sigma_{2}\right)^{2}+\left(\sigma_{2}-\sigma_{3}\right)^{2}+\left(\sigma_{3}-\sigma_{1}\right)^{2}}{2}}
$$

where $\sigma_{1}, \sigma_{2}, \sigma_{3}$ are the principal stresses. Figure 3 shows the von Mises stress for simulation no.9 (Cutting speed $180 \mathrm{~m} / \mathrm{min}$, feed rate $0.15 \mathrm{~mm}$, and axial depth $2.0 \mathrm{~mm}$ ) after $80 \mathrm{~mm}$. Most of the tensile stress $\sigma_{V}$ appears at the cutting tool edge. The von Mises criterion states that failure occurs when the energy of distortion reaches the same value as the energy for yield/failure in uniaxial tension. Mathematically, this is expressed as (Schey, 2000):

$$
\frac{1}{2}\left[\left(\sigma_{1}-\sigma_{2}\right)^{2}+\left(\sigma_{2}-\sigma_{3}\right)^{2}+\left(\sigma_{3}-\sigma_{1}\right)^{2}\right] \leq \sigma_{y}^{2}
$$

The yield strength and ultimate tensile strength for the coated carbide cutting tool used in this simulation are 600 and $800 \mathrm{MPa}$, respectively. The von Mises stress at region 9 is $4488 \mathrm{MPa}$, which is higher than the yield strength and the ultimate tensile strength of the coated cutting tool. This stress can cause permanent damage to the cutting tool because this stress is beyond the ultimate tensile strength and yield strength. Cutting speed, feed rate, and axial depth for this simulation are very high and this causes the high stress at the cutting edge, because high cutting speed, feed rate, and axial depth can cause high force in milling (Alauddin, Mazid, EL Baradi, \& Hashmi, 1998; Kadirgama $\&$ Abou-El-Hossein, 2005). The radial depth for every simulation is $3.5 \mathrm{~mm}$. This factor also contributes to higher stress. At region 1, at the cutting tool and chip contact, the von Mises stress is $501 \mathrm{MPa}$, whereas the yield strength and ultimate strength of the workpiece are 359 and $759 \mathrm{MPa}$. The workpiece starts to deform because the stress is above its yield strength.

Figure 4 shows the von Mises stress for simulation no. 3 (Cutting speed 100 $\mathrm{m} / \mathrm{min}$, feed rate $0.2 \mathrm{~mm} / \mathrm{rev}$, axial depth $1.5 \mathrm{~mm}$ ). The stress at the cutting tool edge (region 5) is $1345 \mathrm{MPa}$. The von Mises stress is lower compared with that in simulation run no. 9. However, even though the stress is still higher than the yield strength and ultimate tensile strength, the damage should be less severe compared with simulation no.9. At region 3, the stress for the contact point of the cutting tool and chip is $577 \mathrm{MPa}$. This value is almost the same as in simulation no. 9. From the von Mises stress distribution, shown in Figures 3 and 4, it can be seen that most of the tensile stress $\sigma_{V}$ is located at the edge of the cutting tool. The stress distribution also shows that the stress is lower under the cut surface and that it increases gradually near the cutting edge. High force is needed at the tool edge for workpiece penetration, and this indirectly increases the stress at the tool edge. This distribution of the stress is the same for both cases. The 
velocity vectors around the tool tip for simulation no. 9, shown in Figure 5, clearly show the plastic flow of the material around the cutting edge. The same trend of flow was also observed by Movahhedy, Gadala, \& Altintas (2000). Figure 6 shows the 3D picture for von Misses stress distribution for simulation no. 9. Table 3 shows the average value of the von Mises stress at the cutting tool edge for every simulation. This value will be investigated through statistical methods to determine the relationship between the variables (cutting speed, feed rate and axial depth) and the response (von Mises Stress).

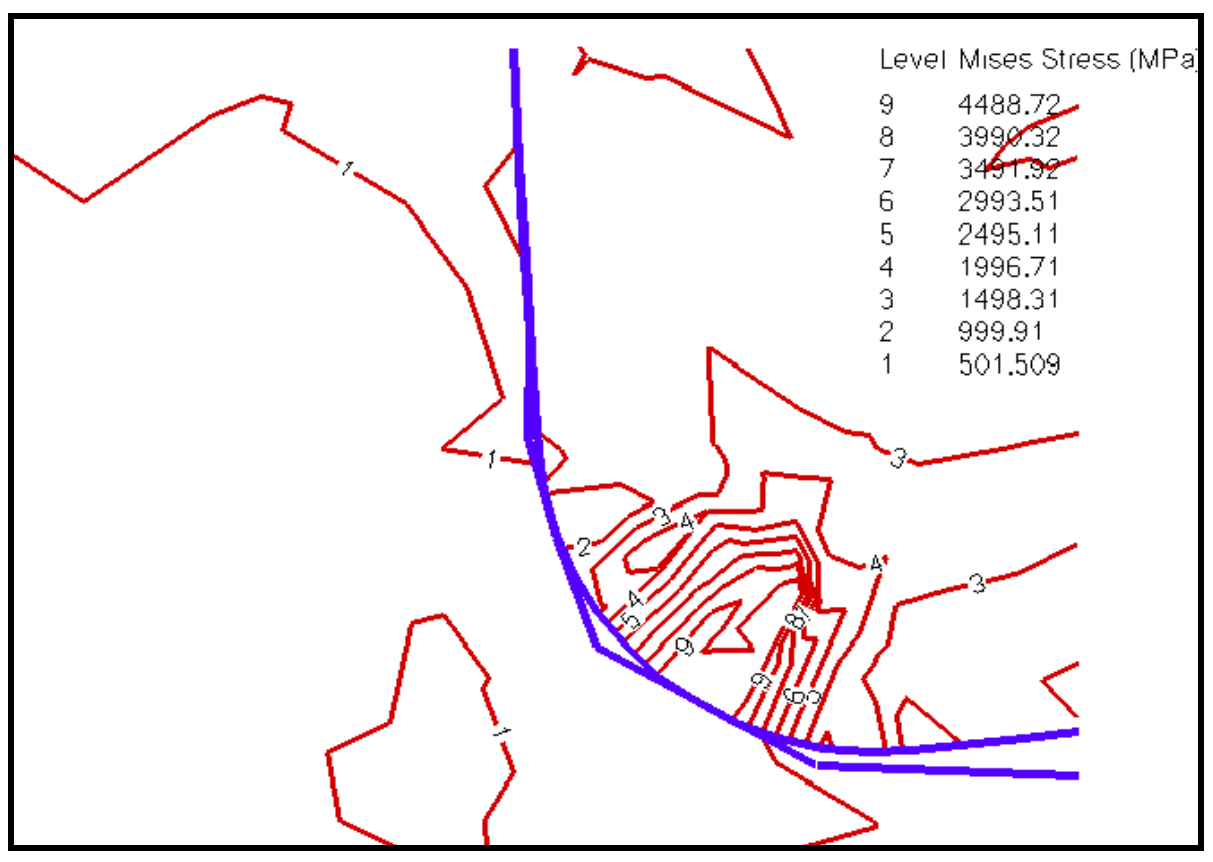

Figure 3. von Mises stress for simulation no. 9

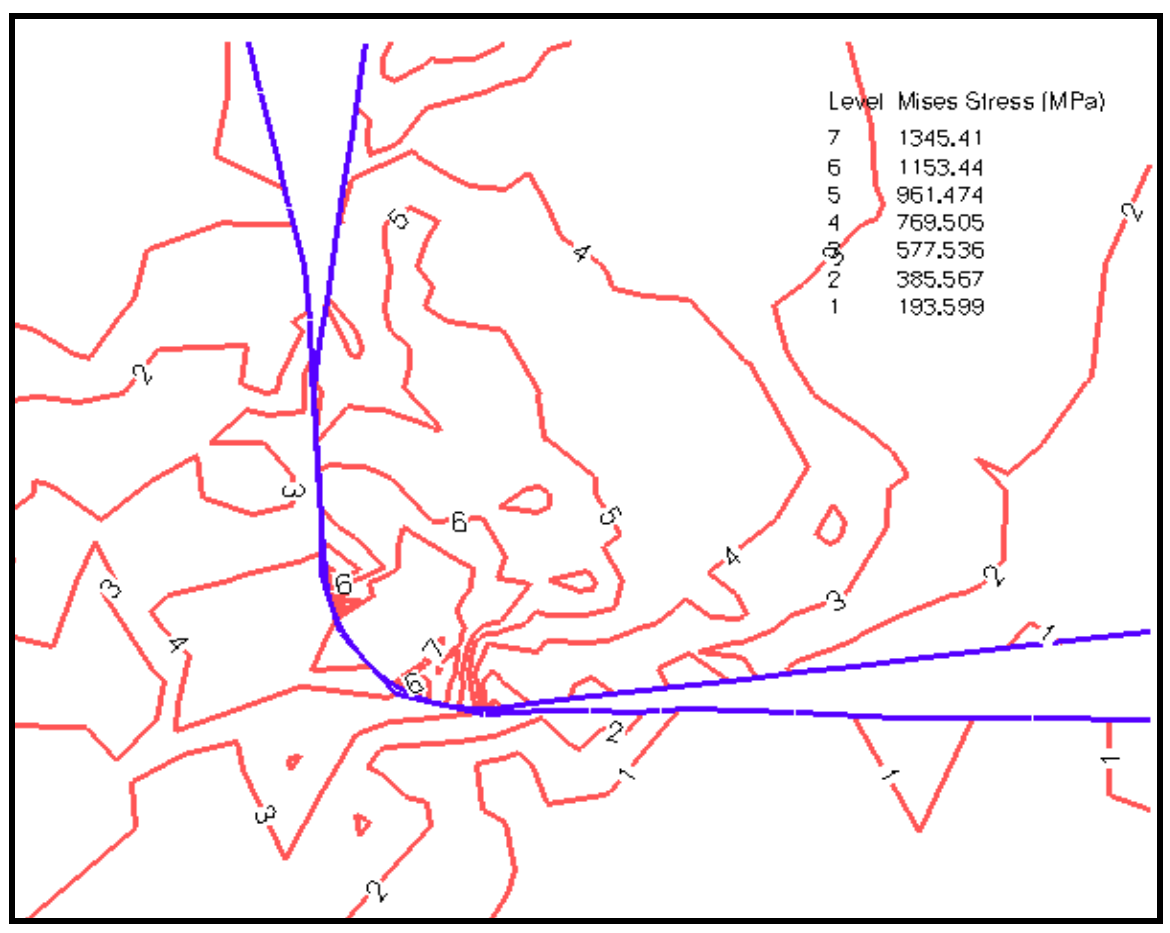

Figure 4. von Mises stress for simulation no. 3 


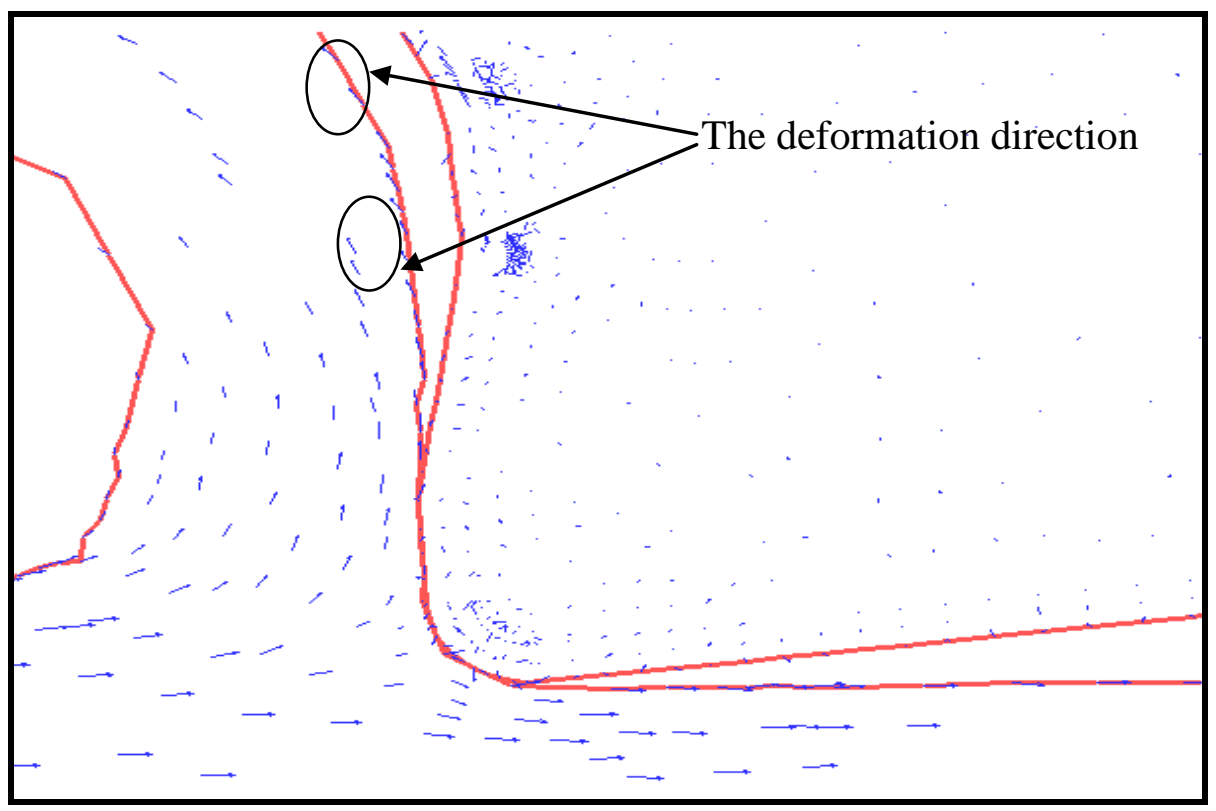

Figure 5. Velocity vectors for simulation no. 9

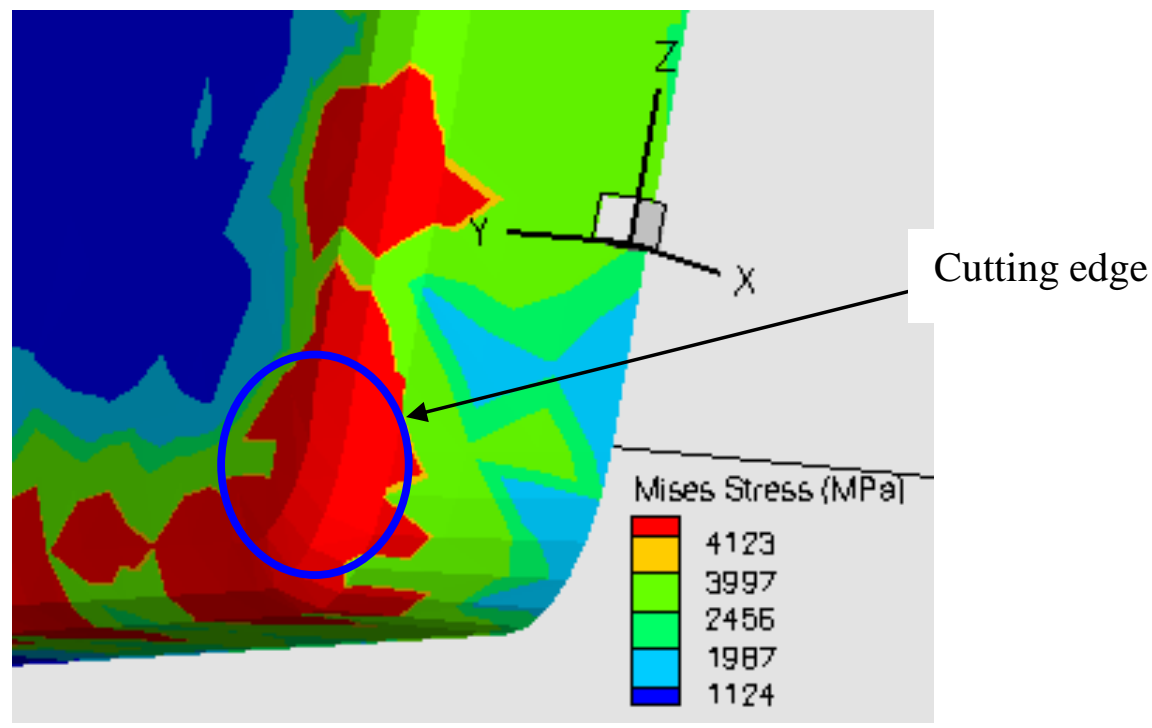

Figure 6. 3D picture for von Misses stress distribution for simulation no. 9

\section{CONCLUSION}

In the milling operation, cutting speed, feed rate, and axial depth play the major role in producing high stresses. The von Mises stress distribution also shows that the stress is lower under the cut surface and that it increases gradually towards the cutting edge. The highest compressive stress, $\sigma_{x x}$ appears at the cutting edge. Most of the tensile stress, $\sigma_{V}$ appears at the edge of the cutting tool. The stress distribution also shows that the stress is lower under the cut surface and that it increases gradually near the cutting edge. High force is needed at the tool edge for workpiece penetration, and this indirectly increases the stress at the tool edge. This distribution of stress is the same for both cases. 


\section{REFERENCES}

Alauddin, M., Mazid, M. A., EL Baradi, M. A., \& Hashmi, M. S. J. (1998). Cutting forces in the end milling of Inconel 718. Journal of Materials Processing Technology, 77, 153-159.

Henriksen, E. K. (1951). Residual stresses in machined surfaces. Transactions ASME, Journal of Engineering for Industry, 73: 69-76.

Kadirgama, K., \& Abou-El-Hossein, K. A. (2005). Force prediction model for milling 618 tool steel using response surface methodology. American Journal of Applied Sciences, 2(8), 1222-1227.

Komvopoulos, K., \& Erpenbeek, S. A. (1991). Finite element modelling of orthogonal cutting. Journal of Engineering for Industry-Transactions of the ASME, 116(3), 289-297.

Konig, W., Berktold, A., \& Koch, K. F. (1993). Turning versus grinding-a comparison of surface integrity aspects and attainable accuracy. Annals of the CIRP, 42(1), 39-43.

Kono, Y., Hara, A., Yazu, S., Uchida, T., \& Mori, Y. (1980). Cutting performance of sintered CBN tools, Cutting tool materials. Proceedings of the International Conference, American Society for Metals, Ft. Mitchell, KY, pp. 218-295.

Kudo, H. (1965). Some new slip-line solutions for two-dimensional steady state machining. International Journal of Mechanical Science, 7, 43-55.

Lee, E. H., \& Shaffer, B. W. (1951). The theory of plasticity applied to a problem of machining. Journal of Applied Mechanics, 18, 405-413.

Liu, C. R., \& Barash, M. M. (1982). Variables governing patterns of mechanical residual stress in a machined surface. Journal of Engineering for IndustryTransactions of the ASME, 104, 257-264.

Liu, R., \& Guo, Y. B. (2000). Finite element analysis of the effect of sequential cuts and tool-chip friction on residual stresses in a machined layer. International Journal of Mechanical Sciences, 42,1069-1086.

Matsumoto, Y., Barash, M. M., \& Liu, C. R. (1986). Effects of hardness on the surface integrity of AISI 4340 steel. Journal of Engineering for Industry-Transactions of the ASME, 108, 169-175.

Movahhedy, M., Gadala, M. S., \& Altintas, Y. (2000). Simulation of the orthogonal metal cutting process using an arbitrary Lagrangian-Eulerian finite element method. Journal of Materials Processing Technology, 103, 267-275.

Okushima, K., \& Kakino, Y. (1971). The residual stresses produced by metal cutting, Annals of the CIRP, 10(1), 13-14.

Schey, J. A. (2000). Introduction to manufacturing processes. New York: McGraw Hill.

Shih, A. J. (1996). Finite element analysis of orthogonal metal cutting mechanics. International Journal of machine Tools and Manufacturing, 36(2), 255-273.

Shih, A. J., \& Yang, H. T. Y. (1993). Experimental and finite element predictions of the residual stresses due to orthogonal metal cutting. International Journal for Numerical Methods in Engineering, 36(9), 1487-1507.

Shih, A. J., Chandrasekar, S., \& Yang, H. T. Y. (1990). Fundamental issues in machining. ASME PED, 43, 11.

Strenkowski, J. S., \& Carroll, J. T. (1985). A Finite element model of orthogonal metal cutting. Journal of Engineering for Industry-Transactions of the ASME, 107(4), 349-354. 
Tonshoff, H. K., Wobker, H. G., \& Brandt, D. (1995). Tribological aspects of hard turning with ceramic tools. Journal of the Society of Tribologists and Lubrication Engineers, 51, 163-168.

Ueda, K., \& Manabe, K. (1993). Rigid-plastic FEM analysis of three-dimensional deformation fiels in chip formation process. Annals of the CIRP, 42(1), 35-38.

Wu, D. W., \& Matsumoto, Y. (1990). The effect of hardness on residual stresses in orthogonal machining of AISI 4340 steel. Journal of Engineering for IndustryTransactions of the ASME, 112, 245-252. 